\title{
Las prácticas políticas de los jóvenes mapuche en Santiago entre 1998 y 2011 Felipe Curin Gutiérrez ${ }^{1}$
}

\author{
Fecha de recepción: 19 de noviembre de 2015 \\ Fecha de aprobación: 12 de enero de 2016
}

\begin{abstract}
Resumen
Desde el primer asentamiento mapuche en la capital de Chile, hacia los años 30 y 40 del siglo $\mathrm{XX}$, se tienen registros y testimonios de las experiencias de asociatividad mapuche con fines políticos, sea en partidos políticos, sindicatos y organizaciones populares. Con la dictadura toda forma de organización oficial es prohibida y hacia finales de los 80 y principios de los 90 surgen, en Santiago de Chile, organizaciones autónomas e independientes del Estado, que tienen como consigna la autonomía y la autodeterminación mapuche. De ahí en adelante surgen variadas experiencias de asociatividad mapuche en la ciudad y muchas de estas experiencias reivindican la historicidad de migración forzada como configuración de un actor político, y la posibilidad de nuevas identidades mapuche en la ciudad como una posición política. Las nuevas generaciones de mapuche nacidos y criados en Santiago aprehenden y asumen su historia como un quiebre epistemológico en sus vidas, provocando un fenómeno de mapuchización, que refiere a la aprehensión política de su identidad e historia familiar, expresada en las múltiples prácticas individuales y colectivas a las que se les atribuye un sentido estrictamente político.
\end{abstract}

Palabras clave: diáspora mapuche, mapuchización, jóvenes mapuche, mapuchismo

\section{Political practices of young mapuche in Santiago between 1998 and 2011}

\begin{abstract}
Since the first Mapuche settlement in the Chilean capital, by the years 30s and 40s of the Twentieth Century, there are records and testimonies of experiences of Mapuche partnerships for political purposes, whether in political parties, trade unions or popular organizations. The dictatorship prohibited any form of official organization and in the late 80 s and early 90s, autonomous and independent state organizations emerge in Santiago, advancing Mapuche autonomy and self-determination. Thereafter, varied
\end{abstract}

Licenciado en Sociología y sociólogo profesional de la Universidad Católica Silva Henríquez. Estudiante de la Maestría en Investigación Educativa de la Universidad Veracruzana, México. Contacto: felipecuring@gmail.com 
experiences of Mapuche partnerships emerged in the city; many of them defend the historicity of forced migration as a political actor, and the possibility of new Mapuche identities as a political position in the city. The new generations of Mapuche - born and raised in Santiago - apprehend and assume their history as an epistemological break in their lives, causing a phenomenon called mapuchizacion, which refers to the political apprehension of their identity and family history, expressed in the many individual and collective practices with a strictly political sense.

Keywords: Mapuche diaspora, mapuchización, young Mapuche, mapuchismo

\title{
As práticas políticas dos jovens mapuche em Santiago entre 1998 e 2011
}

\begin{abstract}
Resumo
A partir do primeiro assentamento Mapuche na capital do Chile, entre os anos 30 e 40 anos do século XX, há registros e testemunhos das experiências de associatividade Mapuche para fins políticos, seja nos partidos políticos, sindicatos e organizações populares. Com a ditadura toda forma de organização oficial é proibida e no final dos anos 80 e início dos anos 90 emergem em Santiago de Chile, organizações autônomas e independentes do Estado, que tiveram como consigna a autonomia e autodeterminação Mapuche. Em diante, surgiram diversas experiências de associatividade Mapuche na cidade e muitas destas experiências reivindicam a historicidade da migração forçada como configuração de um ator político, e a possibilidade de novas identidades Mapuches na cidade como uma posição política. As novas gerações de Mapuches nascidos e criados em Santiago apreendem e assumem sua história como uma ruptura epistemológica em suas vidas, provocando um fenômeno de mapuchización, que se refere à apreensão política da sua identidade e história da família, expressada nas diversas práticas individuais e coletivas as que possuem um sentido estritamente político.
\end{abstract}

Palavras-chave: diáspora Mapuche, mapuchización, jovem mapuche, mapuchismo

\section{Introducción}

El estudio y la reflexión sociológica acerca de las juventudes en América Latina tiene un vacío en cuanto a jóvenes indígenas se refiere. Existen muy pocos sociólogos que hablan sobre la condición juvenil indígena en Latinoamérica; sin embargo, esto no significa que no existan procesos sociales, culturales y políticos en que los mismos jóvenes de los pueblos originarios son los protagonistas. El reciente libro de Maya Lorena Pérez y Laura Valla- 
dares de la Cruz (2014), Juventudes Indígenas. De hip hop y protesta social en América Latina, es uno de los más valiosos aportes para tener un acercamiento a las distintas realidades que viven los jóvenes pertenecientes a los pueblos originarios en el continente. Si bien los enfoques para analizar a las juventudes fundamentalmente urbanas han sido en las culturas e identidades juveniles, es muy importante analizar las juventudes indígenas en contextos y movimientos políticos. Desde este posicionamiento analizamos las prácticas políticas de los jóvenes mapuche ${ }^{2}$ urbanos.

El movimiento social y político mapuche ha generado una serie de procesos de autorreconocimiento identitario y de adhesión a una lucha, en muchos jóvenes que han nacido y crecido en una de las capitales más neoliberales de América Latina en la actualidad, como es Santiago de Chile. Estos jóvenes son hijos y nietos de personas mapuche migrantes, que abandonaron forzadamente el campo y sus comunidades, generalmente en busca de oportunidades laborales y persiguiendo un mejor futuro económico para sus generaciones. A esto llamamos la "diáspora mapuche", como concepto teórico político.

La investigación considera como hipótesis de trabajo que las actuales generaciones de mapuche, al reconocer su identidad y su historia en situación de proceso de destrucción colonial histórica, y al transformar ese reconocimiento en demanda política hacia el Estado chileno, están expresando simultáneamente un núcleo de pensamiento y de acción diferente a las generaciones anteriores. En consecuencia, sus formas de organización, su discurso político, así como sus prácticas políticas cambian radicalmente, ya que están enmarcadas en un tiempo social en el que la forma tradicional de hacer política (la partidista) tiende a una

La palabra "mapuche", en la lengua mapudungun ya es plural, por lo tanto en este trabajo nos referiremos a "los mapuche" respetando las normas de la lengua mapudungun. A continuación se utilizarán las normas de escritura del grafemario mapuche unificado. 
escasa representatividad y alta desconfianza social al interior de la juventud mapuche.

Este trabajo busca conocer los sentidos que los jóvenes mapuche, que viven en Santiago y que no han sido criados en contextos de comunidades rurales y pertenecen o pertenecieron a una organización, le atribuyen a sus prácticas políticas, en medio de un proceso de movimiento social en el cual participan y son protagonistas. Para introducirnos a este proceso sociopolítico, es menester realizar un recorrido histórico sobre las generaciones mapuche que llegaron a las ciudades y específicamente a Santiago en la segunda mitad del siglo XX. Es importante señalar que el fenómeno de la migración no es el único hecho importante en la historia mapuche contemporánea, sino también los procesos de resiliencia y reinvención de los proyectos de vida, y sus prácticas políticas entre 1998 y 2011.

\section{Desestructuración y reinvención de la sociedad mapuche; de wallmapu a la diáspora}

Cuando se habla del proceso de migración y asentamiento urbano de la sociedad mapuche en las grandes ciudades del sur de Chile, como Temuco y Concepción, y particularmente en Santiago, destino inevitable del migrante interno en el país, es ineludible hacer hincapié en las razones y motivos estructurales que condicionaron este fenómeno. Sin embargo, no es lo único por destacar de todo este proceso, sino también cuál fue la reacción del pueblo mapuche, forzado a migrar de sus espacios de origen, y la reinvención que experimentaron en sus proyectos de vida ante este proceso social, político y económico que les tocó vivir.

Según los investigadores de la migración mapuche a la ciudad, este proceso se divide en tres etapas; en primer lugar "empobrecimiento" (Saavedra, 2002); en segundo "proletarización", expresada en el trabajo asalariado, y finalmente "emigración", especialmente de jóvenes y mujeres hacia centros urbanos (Imilan y Álvarez, 2008). 
La escasez y la pauperización de las tierras, producto de la radicación y usurpaciones que fueron llamadas "reducciones" hecha en muchos casos a punta de asesinatos de familias enteras, situación que no tiene otro nombre más que etnocidio-, se trasformó en la principal causa de las migraciones durante la primera mitad del siglo XX, sobre todo los años 30 y 40 (Curivil, 2006). El destino inicial fueron los fundos cercanos a las reducciones, luego los espacios urbanos cercanos a los campos, para posteriormente dirigirse tanto a las ciudades sureñas como al lejano Santiago.

La mayoría de los casos de migración se relacionan con razones estructurales, pauperización de tierras y condiciones de extrema pobreza; sin embargo, existen también casos en que la migración se produjo por el atractivo de las actividades laborales de la ciudad; por el contrario, la vida en el campo ya no era atractiva. Tal es así que en los años 60 muchos mapuche trabajan de panaderos, llegando a ser alrededor de 6.000 personas mapuche registradas en la Confederación Nacional de Trabajadores Panificadores CONAPAN (Imilan y Álvarez, 2008). Sumado a las reducciones de tierra, empobrecimiento y proletarización del pueblo mapuche, con la llegada de la dictadura la reducción del territorio mapuche se profundizó. Conjuntamente con ello, la firma del Decreto con Fuerza de Ley $N^{\circ} 2568$, conocido como la ley de división de tierras, por parte de la junta militar, afectó radicalmente la dinámica interna de las comunidades mapuche provocando la ruptura de las solidaridades socioculturales, con el consiguiente aumento de conflictos familiares, lo cual trajo consigo un alto impacto en la cohesión interna de las comunidades. En ese sentido, la investigación contemporánea sobre la problemática mapuche apunta a considerar la aplicación de dicha ley como el punto de inflexión en las tendencias migratorias del pueblo mapuche, aumentando su flujo respecto de los periodos anteriores (Valdés, 2003).

La dinámica de migración campo-ciudad en los años 80 solo se profundizó, con la especificidad en la variable género y sexo. 
Los datos del Censo de 1992 dejaron en evidencia que la población mapuche migrante estaba compuesta fundamentalmente por mujeres y jóvenes. Ello se explica porque las mujeres tienen una fuente directa de trabajo en la cual desempeñarse: trabajadoras de casas particulares; por el contrario, los hombres se ven en la obligación de aprender nuevos oficios para poder desarrollar su capacidad laboral. Según Saavedra (2000):

Parece razonable pensar que no más de un $12 \%$ de la población mapuche se gana la vida como campesino por cuenta propia. El resto se ha desvinculado del trabajo en lo que fueron sus últimas comunidades. Un $73,2 \%$ de la población mapuche económicamente activa se ha proletarizado y trabaja como asalariado y como empleado. (Saavedra, 2000, p. 15).

Según la encuesta de Caracterización Socioeconómica Nacional (Casen) de 2009, la población que se autoidentifica como perteneciente a los pueblos originarios alcanza a 1.188.340 personas, lo que equivale al $7 \%$ de la población total del país. Donde un $68,9 \%$ de la población indígena vive en contexto urbano.

El último Censo de población de 2012 arrojó que un total de 1.508.722 personas se reconocen como mapuche dentro del territorio del Estado chileno. Donde un total de 450.503 son personas entre los 15 y 29 años, considerando a hombres y mujeres dentro del rango etario denominado "jóvenes", objeto de estudio de este artículo.

El resultado de todos estos procesos de migración que hemos relatado es de un millón y medio de personas correspondientes al 10\% de la población total de Chile aproximadamente. Donde un total de 564.234 personas, entre hombres y mujeres, viven en la Región Metropolitana y pertenecen a la diáspora mapuche en Santiago respecto de su lugar geográfico de origen, Wallmapu (país mapuche). 


\section{Prácticas políticas de los mapuche en la ciudad: un breve recorrido}

La participación política mapuche en Santiago comienza a mediados de la década de los 50 . El mapuche migrante ya era parte de los diferentes sindicatos de obreros que trabajaban fundamentalmente de panaderos, y de las organizaciones populares de pobladores exigiendo vivienda, lógica organizacional impulsada por el Movimiento de Izquierda Revolucionaria (MIR) ${ }^{3}$. Ya había presencia mapuche en las dirigencias de aquellos sindicatos y organizaciones. (Caniuqueo, Levil, Mariman y Millalen, 2006).

No obstante la participación mapuche en los sindicatos de trabajadores y organizaciones populares, en los años 60 la dirigencia mapuche en Santiago también mantenía vínculos con los partidos políticos de la época. Sergio Caniuqueo relata lo siguiente: "A fines de los 60 pareciera ser que los partidos pasan a ser la estrategia para algunos mapuche que ven su inserción en ellos como un fin para hacer política ya no como pueblo, sino como clase (obreros)" (Caniuqueo et al., 2006, p. 193). Los bloques políticos, sobre todo los de centroizquierda, contaron entre sus filas con militantes mapuche y no mapuche, quienes participaron conjuntamente en las reformas agrarias de los gobiernos de Eduardo Frei Montalva y Salvador Allende.

Así acontece la historicidad de la dirigencia mapuche, que hacia finales de la década de 1960 y principios de 1970 estaba muy involucrada en la política, manteniendo autonomía para los asuntos internos en las comunidades mapuche, y para el exterior se articulaba con partidos y movimientos que le permitían conversar con las autoridades de gobierno (Martínez, 2004).

A partir de septiembre de 1973 se inicia una operación de exterminio de estas organizaciones debido al golpe de Estado, periodo o proceso político en Chile que da lugar a un régimen que se extiende hasta marzo de 1990). 
A partir de la prohibición de los partidos políticos durante la dictadura en Chile, comenzó otro proceso de desmovilización de la sociedad chilena y también mapuche. Sin embargo, esta situación provocó que un sector del mundo mapuche asumiera una posición muy crítica hacía la militancia partidaria, a partir de la situación de indefensión en que quedaron los mapuche (Martínez, 2009).

En medio de este complejo escenario surgieron organizaciones aparentemente despolitizadas, como los Centros Culturales Mapuche (CMM), que luchaban contra la división de títulos comunitarios (títulos de merced), y posteriormente Ad Mapu, que luchaba por defender la propiedad comunitaria de la tierra ante las políticas de privatización de la dictadura. Según Martínez (2009), una serie de situaciones comenzaron a resquebrajar el consenso interno de Ad Mapu, y se manifestaron las distintas matrices de pensamiento político al interior del movimiento mapuche que muchas veces estaban en tensión y contradicción. Algunos de los historiadores del proceso señalan que las tendencias políticas partidarias y las disputas internas por el liderazgo produjeron una división en la dirigencia de la organización.

Es muy importante para este trabajo señalar que existe una pluralidad en los marcos de sentido de la dirigencia mapuche, despejando así esa idea algo ingenua de que los dirigentes mapuche tenderían a una cierta unidad natural de acción política (Martínez, 2009). Este elemento es clave para este trabajo, ya que aquella pluralidad de los marcos de sentido de la que habla este autor es la que se constata en este trabajo y se estudia en los jóvenes mapuche en el periodo posdictadura en Santiago de Chile. Finalmente, durante este periodo la dirigencia mapuche apoyó la lucha por la democratización del país y la candidatura de Aylwin en 1989, a cambio de que éste promoviera una ley indígena y una corporación estatal de desarrollo. También se comprometió a procesar sus demandas de manera pacífica y por los nuevos canales institucionales que se crearían para este efecto (Bengoa, 1999). 
Posteriormente, en lo que algunos llaman la nueva democracia o la vuelta a la democracia en 1990, comienza un nuevo proceso sociopolítico en que se manifiesta una nueva manera de organización entre los jóvenes en Chile, y también los jóvenes mapuche que viven en la ciudad, hijos y nietos fundamentalmente de aquellos que llegaron desde la Araucanía en la década de los sesenta, quienes no están involucrados con la dirigencia mapuche adulta y que comienzan a asumir su etnicidad como una demanda política además de cultural.

Dependiendo de la perspectiva que se asuma respecto del "conflicto", se puede hacer el análisis a partir de los años noventa o posdictadura. Mi posición es clara, dada mi pertenencia al pueblo nación mapuche; sin embargo existen visiones como la de Sergio Villalobos, otro historiador muy influyente en Chile (sobre todo en los textos escolares), que afirma primero la noción de "etnicidad ficticia" con la que aborda el "activismo mapuche"; además señala que la situación es una "mancha que ensucia la caligrafía estándar del archivo nacional y enturbia la transparencia del universalismo jurídico y fáctico de estos, así llamados, tiempos liberales" (Villalobos, 2007, p. 110).

Para finalizar este recorrido se recogen algunas perspectivas de análisis que realiza el historiador mapuche Fernando Pairican (2012), quien proyecta al Aukiñ Wallmapu Ngulam (Consejo de Todas las Tierras, CTT) como el sembrador de la ideología mapuche posdictadura, proyecto político que fue llamado "autodeterminación". Pairican señala que, mientras gran parte de la literatura de la transición apunta a la despolitización de la sociedad, una parte del pueblo mapuche, encabezado por el CTT, generó las primeras siembras ideológicas de una nueva forma de hacer política, que explotaría con mayor notoriedad en 1997, con la quema de los tres camiones forestales en la zona de Lumaco. Mostró con ello una nueva manera de operativizar los planteamientos ideológicos del pueblo mapuche, además del surgimiento de una nueva camada de organizaciones que se plantearon como autonómicas e independientes del Estado (Pairican, 2012). 


\section{Las prácticas políticas de los jóvenes mapuche desde 1998 en adelante}

Desde diciembre del año 1997 las manifestaciones del movimiento político mapuche tomaron un rumbo diferente. La violencia política se hizo sentir en las calles, con la recordada quema de camiones en Lumaco. Esta nueva realidad en el escenario político mapuche era algo que tal vez se veía venir, si pensamos que, luego de la marcha por la resistencia de los 500 años de los pueblos originarios, en 1992, juntamente con la declaración ideológica del CTT, algunos jóvenes de la comuna de Cerro Navia, posteriormente constituidos como el colectivo Odiokratas, manifestaron su descontento y profunda crítica al modelo colonial capitalista chileno y las herencias de la dictadura cívico militar, atacando el Círculo Español.

... dejamos la cagá... pero ahí no era odiokratas, en ese tiempo dejamos la cagá en círculo español, pero una wea que todavía andábamos peleando con los españoles por una wea de cultura culiá no más... todavía veíamos al enemigo como el español, fuimos a darle jugo al círculo español, dejamos la cagá... (Entrevista realizada a David y Simón Aniñir, en diciembre de 2012).

La compleja situación sociopolítica en la que se encuentran los jóvenes ${ }^{4}$ mapuche, educados bajo los patrones establecidos por el Estado chileno y que hoy son parte de las personas indígenas que viven en la Región Metropolitana, que han sido formadas dentro del proyecto republicano chileno, en una cultura distinta a la de sus abuelos y ancestros -partiendo desde la cosmovisión y también la lengua, elementos fundamentales en la construcción del sujeto-, es de una tensión constante. Posterior al hito de la conmemoración de los 500 años de resistencia, estalla una suerte

\footnotetext{
4 En este trabajo se entiende el término "jóvenes" desde la noción de Feixa: "Por juventud nos referimos a una amplia escala cronológica -jóvenes de ambos sexos en el rango de edad 12-35-. Este rango de edad indica en qué medida la categoría de edad juventud se ha ampliado, para incluir algunos de los que están legalmente reconocidos en otras sociedades como los niños, y algunos que están legalmente reconocidos en otras sociedades como adultos (Feixa, 2010, p. 2).
} 
de emergencia de la conciencia indígena (Bengoa, 2000), sumada a la aparición de la Coordinadora Arauco Malleco y, antes de ella, las nuevas generaciones de mapuche aprehenden y asumen su historia como un quiebre epistemológico en sus vidas, y la expresan a través de sus prácticas y/o acciones políticas. Los jóvenes que viven en los barrios populares de Santiago señalan aquel proceso como mapuchizarse; algunos autores, como Osorio (2009), señalan este proceso como un tránsito social-cultural-identitario al que llaman De Chorizo a weichafe.

Fundamental en este proceso sociocognitivo, entendido como un tránsito en su historia social cultural, fue la Coordinadora de Comunidades Mapuche en Conflicto (CAM). Esta organización se volvió una alternativa real como destino de militancia y de combate por el "control territorial" y la recuperación de tierras5. Sin embargo, la lucha y la reivindicación mapuche no es solo territorial, ya que desde el mismo movimiento mapuche en Santiago surge el concepto de "mapuche urbano" (Warriache: gente de la ciudad): Esta reflexión, surgida desde el grupo odiokratas, se transformó en una reflexión crítica colectiva y decantó en la necesidad de resignificar y cuestionar qué es lo mapuche, y comprenderse a sí mismo desde sus diversas trayectorias de vida familiar, y sus múltiples diferencias y facetas en la diáspora, como una historia a reivindicar y como un actor político enteramente competente y real en el pueblo mapuche actual. Uno de los integrantes del colectivo odiokratas afirma que esta reflexión en torno al warriache surge como una instancia "para poder buscarnos, resignificarnos como mapuche estando en la ciudad (Entrevista a David Aniñir, diciembre de 2012), ya que la reivindicación era únicamente por el territorio, el tema en torno a la urbanidad estaba invisibilizado.

El poema "Mapurbe", creado por David Aniñir (2005), en aquellos tiempos integrante del colectivo odiokratas, ha sido objeto de estudio por muchos investigadores de las ciencias socia-

Léase Osorio, Liber (2009). De Chorizo a weichafe: nuevos elementos culturales en la identidad mapuche en Santiago, 1997-2009. 
les, pero también fue un manifiesto que configuró a un sujeto político al interior del pueblo mapuche (no exento de críticas y subvaloraciones), que también es una voz que reivindica su historia, desde una conciencia de indio y poblador 6 .

Somos Mapuche de hormigón/ Debajo del asfalto duerme nuestra madre/ Explotada por un cabrón/ Nacimos en la mierdópolis por la culpa del buitre cantor/Somos lo que quedamos en pocas partes/ El mercado de la mano de obra/ Obra nuestras vidas / Y nos cobra/ Madre, vieja mapuche, exiliada de la historia/ Hija de mi pueblo amable/ Desde el sur llegaste a parirnos / Un circuito eléctrico rajó tu vientre/ Y así nacimos, gritándoles a los miserables/ MARRI CHI WEW!!!!/ En lenguaje lactante. (Aniñir, 2005, s/p)

Del proceso histórico que relata el poeta Aniñir se desprenden muchos acontecimientos interesantes que vendrán a explicar muchos de los hitos y maneras de pensar lo mapuche en la ciudad. El solo hecho de asumir la historia mapuche urbana y popular presenta una apertura a las identidades mapuche, y al mismo tiempo genera una ruptura con la tendencia de ruralizar lo mapuche y lo indígena, aquella noción que dice que los mapuche solo están en el sur y que el movimiento social/político depende únicamente de lo que sucede en las comunidades. Aun sabiendo que la lucha por el territorio y las tierras es fundamental, aquello no es la única instancia en donde se está dando el weichan (lucha), hay otros campos (Bourdieu, 1995) o territorios ${ }^{7}$, en donde existen weichafe (guerrero) que trabajan arduamente por transformar espacios de poder en los que se generen reflexiones críticas acerca de la situación de conflicto y colonialismo interno que ejerce el Estado chileno sobre el pueblo mapuche, y establecer aquellas matrices que proyecten los

\footnotetext{
Revista Rufián $\mathrm{N}^{\mathrm{o}}$ 11, Warriache, Crónicas de la resistencia mapuche en la ciudad http:www.rufianrevista.org

7 Amplitud del campo léxico: ampliación del significado, no se limita a un solo campo, sino que interviene en otros.
} 
análisis y pensamientos mapuche respecto del proyecto sociopolítico de autodeterminación. Sin embargo, no podemos desconocer la importancia que tiene la lucha por la tierra, para las comunidades, para el pueblo y para el movimiento social mapuche.

La presencia de jóvenes en este proceso ha sido fundamental para la mapuchización de las nuevas generaciones de mapuche en diáspora. Las muertes de jóvenes como Alex Lemun (2002), Matías Catrileo (2008), Julio Huentecura (2004), Jaime Mendoza Collio (2009), Rodrigo Melinao (2013) y un centenar de detenciones en los enfrentamientos directos con la policía, ha generado un despertar del oído mapuche y una apertura del ojo mapuche de las nuevas generaciones. Fuera de la violencia política existen otros elementos muy relevantes en este conflicto, ya que la diversidad de trayectorias de vida de la diáspora mapuche en Santiago también diversifica y amplía las posibilidades de identidad mapuche, como también las demandas. Como hemos mencionado, las demandas se vinculan con territorios simbólicos, que construyen sociedades como la educación en el idioma mapuche (mapudungun), y todos los derechos colectivos que tiene todo pueblo heterogéneo como el pueblo mapuche.

En este sentido, la categoría "Weichafe" también tiene una ampliación hacia los campos en los que se proyecte una lucha por instalar políticamente el conocimiento mapuche en cada ámbito o campo de la sociedad, como la salud, la educación, los modos de producción, el arte, la lengua, etc. Entendiendo la sociedad como una red de redes que configuran la totalidad del mundo de la vida.

\section{Las organizaciones que durante el proceso expresaron distintas ideas políticas}

En este estudio se escogieron seis organizaciones que proporcionan diferentes expresiones de la matriz política mapuche en Santiago de Chile, estas son: Odiokratas, Meli Wixan Mapu, Trawun Wekeche, Kilapan, Codemu (Colectivo de Estudiantes Universitarios Mapuches y Federación Mapuche de Estudiantes, FEMAE). 
A continuación unos cuadros descriptivos de cada organización ${ }^{8}$.

1. Meli Wixan Mapu

\begin{tabular}{|l|l|}
\hline Nombre de la organización & Meli Wixan Mapu \\
\hline Fecha de la fundación & 1990 aproximadamente. \\
\hline Proyección del Movimiento & Construcción de un proyecto político. \\
\hline Dependencia de la Organización & Autónomo. \\
\hline Sede o lugar de ubicación & Andes 2647, Santiago Centro. \\
\hline Frecuencia de encuentros & Activo. \\
\hline Propuesta política & $\begin{array}{l}\text { Construir, crear y rescatar cultura e } \\
\text { identidad desde la urbanidad, en el } \\
\text { proceso de liberación del pueblo ma- } \\
\text { puche. }\end{array}$ \\
\hline Acciones & $\begin{array}{l}\text { Boletín, foros, ferias, marchas, } \\
\text { universidad libre Wenceslao Paillal, } \\
\text { eventos culturales y artísticos, etc. }\end{array}$ \\
\hline Red con otros movimientos & $\begin{array}{l}\text { Comunidades mapuche, movimien- } \\
\text { tos sociales. }\end{array}$ \\
\hline
\end{tabular}

La agrupación Meli Wixan Mapu, es una de las organizaciones mapuche autónomas más antiguas y relevantes de la diáspora, muchas de las otras organizaciones que estudiamos en este trabajo han sido formadas en las actividades que genera "la Meli". Su propuesta es la construcción de un proyecto político mapuche. Para ello han creado instancias de formación, discusión y difusión de la cultura, como ferias, conciertos, foros, videotecas, etc. Sus integrantes asumen una "militancia" política al ingresar y, como organización, son un apoyo fundamental para las comunidades en conflicto en Wallmapu. Una de las actividades más masivas y visibles que organiza la Meli, es la marcha por la resistencia mapuche cada 12 de octubre por la avenida Alameda en Santiago de Chile.

8 La descripción de los cuadros a continuación es propia, y hecha en función de los ámbitos en donde se desenvuelven o desenvolvieron estas organizaciones, y las entrevistas aplicadas. 


\section{Odiokratas}

\begin{tabular}{|l|l|}
\hline Nombre de la organización & Colectivo Odiokratas. \\
\hline Fecha de la fundación & Fines de 1997, principios de 1998. \\
\hline Proyección del movimiento & Movimiento punk-anarkista-mapuche. \\
\hline Dependencia de la organización & Autónomo. \\
\hline Sede o lugar de ubicación & Cerro Navia, Población Colo-Colo. \\
\hline Frecuencia de encuentros & Inactivo. \\
\hline Propuesta política & $\begin{array}{l}\text { Levantar visión crítica sobre el movi- } \\
\text { miento y la identidad mapuche. }\end{array}$ \\
\hline Acciones & $\begin{array}{l}\text { Jornadas culturales, festivales callejeros } \\
\text { de punk (Rock in río Mapocho, melón } \\
\text { con rock, etc.). }\end{array}$ \\
\hline Red con otros movimientos & Colectivos anarquistas \\
\hline
\end{tabular}

El Colectivo Odiokratas es un grupo de jóvenes vecinos que se agrupaban en torno a la barra brava del club de fútbol ColoColo. Todos eran hijos de mapuche migrantes en Santiago. Con el tiempo fueron reflexionando en torno a sus historicidades familiares en común, también en torno al porqué estaban en Santiago y las prácticas mapuche que vivían cotidianamente en sus casas. Toda esta historia que asumían y reivindicaban, sumada a la música punk y su contenido político en torno al anarquismo, resultó en particulares y concurridas actividades en las cuales las expresiones y el discurso venían desde lo mapuche. Finalmente uno de los aportes más significativos del Colectivo Odiokratas es la reflexión acerca de la condición mapuche en la urbanidad; el ensamble de la historia rural en la comunidad y su historia y conciencia de clase estando en los barrios populares de Santiago.

3. Trawün wekeche

\begin{tabular}{|l|l|}
\hline Nombre de la organización & Trawün wekeche. \\
\hline Fecha de la fundación & Principios del año 2000. \\
\hline Proyección del movimiento & $\begin{array}{l}\text { Movimiento estudiantil mapuche } \\
\text { secundario. }\end{array}$ \\
\hline Dependencia de la organización & Autónomo. \\
\hline Sede o lugar de ubicación & $\begin{array}{l}\text { Instituto Nacional, Liceo Carmela } \\
\text { Carvajal. }\end{array}$ \\
\hline
\end{tabular}




\begin{tabular}{|l|l|}
\hline Frecuencia de encuentros & Inactivo. \\
\hline Propuesta política & $\begin{array}{l}\text { Autodeterminación y autonomía de } \\
\text { la nación mapuche. }\end{array}$ \\
\hline Acciones & $\begin{array}{l}\text { Asambleas, marchas, boletín, talle- } \\
\text { res. }\end{array}$ \\
\hline Red con otros movimientos & Movimiento estudiantil. \\
\hline
\end{tabular}

Este colectivo de estudiantes mapuche funcionó en un contexto de las instituciones de educación secundaria más prestigiosas del país, en las que se han formado la mayoría de los presidentes de Chile. En ese contexto se levantaron estudiantes mapuche, con la convicción de que tenían que hacer algo, dadas las circunstancias que estaban aconteciendo en el sur, a partir de la aparición de la Coordinadora Arauco Malleco (CAM) y las movilizaciones por la represa en Ralco. Siempre mirando de cerca el alzamiento zapatista, Trawun wekeche publicaba un boletín al que llamaron Weichañ, y que difundían cada semana dentro del Instituto Nacional. Realizaban actividades de autoformación dentro de la institución y en una recordada actividad quedó demostrada su radicalidad identitaria, cuando en medio de las fiestas patrias chilenas rayaron un muro de la institución con la consigna: "mapuche sí... chilenos jamás".

\section{Organización mapuche kilapan}

\begin{tabular}{|l|l|}
\hline Nombre de la organización & Organización mapuche kilapan. \\
\hline Fecha de la fundación & Desde el año 2003 ya existía. \\
\hline Proyección del movimiento & $\begin{array}{l}\text { Autodeterminación del pueblo ma- } \\
\text { puche. }\end{array}$ \\
\hline Dependencia de la organización & Autónomo. \\
\hline Sede o lugar de ubicación & En casa de algún integrante. \\
\hline Frecuencia de encuentros & Inactivo. \\
\hline Propuesta política & $\begin{array}{l}\text { Control territorial para la liberación } \\
\text { nacional mapuche. }\end{array}$ \\
\hline Acciones & $\begin{array}{l}\text { Asambleas, foros, Füta malon, activi- } \\
\text { dades culturales. }\end{array}$ \\
\hline Red con otros movimientos & $\begin{array}{l}\text { Coordinadora de comunidades en } \\
\text { conflicto CAM. }\end{array}$ \\
\hline
\end{tabular}


La Organización mapuche kilapan es una de las experiencias de asociatividad mapuche urbana de mayor lazo y correspondencia con las coyunturas que ocurren en el sur, probablemente puede ser el "brazo" urbano de la CAM. Sus integrantes eran mayoritariamente adultos, aunque también contaba con participación activa de algunos jóvenes que cumplían un rol fundamental en las relaciones Wallmapu-Santiago. Su proyecto político es idéntico al de la CAM (Pairican, 2011): autodeterminación mediante el control territorial, la reconstrucción del lof para llegar a la liberación nacional. Sus principales actividades tienen que ver con los viajes al sur a visitar las comunidades y a los presos, y las actividades que podían realizar en Santiago para ayudar a las comunidades en conflicto.

5. Colectivo de estudiantes mapuche universitarios

\begin{tabular}{|l|l|}
\hline Nombre de la organización & CODEMU \\
\hline Fecha de la fundación & año 2011 \\
\hline Proyección del movimiento & $\begin{array}{l}\text { Movimiento social mapuche y la } \\
\text { reivindicación de los derechos colec- } \\
\text { tivos del pueblo mapuche. }\end{array}$ \\
\hline Dependencia de la organización & Autónomo. \\
\hline Sede o lugar de ubicación & UAHC, UCSH, ARCIS. \\
\hline Frecuencia de encuentros & Inactivo. \\
\hline Propuesta política & $\begin{array}{l}\text { Instaurar y promover los derechos } \\
\text { educativos del pueblo mapuche. }\end{array}$ \\
\hline Acciones & $\begin{array}{l}\text { Foros, coloquios, talleres, activida- } \\
\text { des culturales. }\end{array}$ \\
\hline Red con otros movimientos & Movimiento estudiantil. \\
\hline
\end{tabular}

El colectivo CODEMU fue una instancia para agrupar a los estudiantes mapuche repartidos en las universidades de Santiago. Si bien el colectivo no logró reunir a todos estos, se planteó como una agrupación que instauraba la temática en las universidades, como un conflicto político entre el Estado chileno y el pueblo mapuche, partiendo de reconocer un estado de colonialismo interno, como proceso de dominación al interior del país, asumiendo que los mapuche que viven en la diáspora son pobres 
y que tienen una conciencia de clase, como también una conciencia de indio. Desde el movimiento estudiantil planteó una descolonización del currículo como un proyecto educativo mapuche, basado en los derechos de los pueblos.

6. Federación mapuche de estudiantes, FEMAE

\begin{tabular}{|l|l|}
\hline Nombre de la organización & FEMAE. \\
\hline Fecha de la fundación & Año 2011. \\
\hline Proyección del movimiento & Creación de la universidad mapuche. \\
\hline Dependencia de la organización & CONFECH, autogestión. \\
\hline Sede o lugar de ubicación & Universidades en Temuco y Santiago. \\
\hline Frecuencia de encuentros & No determinado. \\
\hline Propuesta política & $\begin{array}{l}\text { Derechos políticos y educativos del } \\
\text { pueblo mapuche. }\end{array}$ \\
\hline Acciones & Foros, festivales, asambleas. \\
\hline Red con otros movimientos & Movimiento estudiantil. \\
\hline
\end{tabular}

La Federación mapuche de estudiantes se generó a partir del movimiento estudiantil chileno de 2011, como una instancia en la que se luchara por establecer un currículo educativo descolonizado y darle un sentido educativo a la demanda del movimiento estudiantil, es decir, proponer una educación pública, gratuita e intercultural.

Una de las demandas más emblemáticas de FEMAE era la creación de una universidad mapuche, basada en la experiencia de la CONAIE en Ecuador, quienes lograron la creación de la universidad "Amawtay Wasi" (Sandoval, 2013). Demanda que trascendió a otras organizaciones, en las que había jóvenes estudiantes que participaban en los foros o asambleas que convocaba FEMAE. Allí se reflexionó y se discutió de manera real la posibilidad de la existencia de una universidad mapuche; de ahí surgió por ejemplo la puesta en marcha de la Universidad Libre Mapuche, en Santiago de Chile.

A partir de registrar las organizaciones a mi juicio más importantes del proceso de movilización mapuche entre 1998 y 2011 se 
realizó esta investigación. Se entrevistó a sus integrantes y también se registraron sus actividades y documentos históricos, y sus matrices de pensamiento político. Luego de "etnografiarlas", se pudo establecer ciertos hallazgos en las trayectorias de vida de los jóvenes mapuche, sus prácticas políticas y las luchas de las organizaciones en Santiago.

Esta investigación se presenta como un aporte a la comprensión del movimiento mapuche en Santiago. Romper con el ingenuo y por momentos también colonial pensamiento que tiende a homogeneizar la lucha del pueblo mapuche, entendiendo al pueblo, en cambio, como una sociedad diversa en sí misma, con contradicciones y tensiones internas como cualquier sociedad. También, para romper la tendencia a ruralizar las luchas indígenas en toda la región latinoamericana, perdiendo de vista los procesos de migración forzada de los pueblos originarios al interior de los países, que se relacionan con empobrecimiento de las comunidades, la usurpación de territorios y posteriormente la proletarización de los indígenas en la ciudad. Se trata de saber también cómo luchan actualmente las familias indígenas en las grandes capitales de América Latina para reinventar sus proyectos de vida en procesos de resiliencia colectiva.

\section{Los principales elementos de la mapuchización}

Al etnografiar a estas organizaciones a través de sus integrantes pude advertir que existen hitos en sus trayectorias de vida, que se presentan como quiebres epistemológicos en sí mismos y se vinculan principalmente con tres vicisitudes transversales en todas las personas entrevistadas: la discriminación, los lazos familiares y las instancias educativas que fueron como una inducción a lo mapuche.

A partir de las entrevistas realizadas se puede observar que las experiencias biográficas de los jóvenes mapuche en Santiago son gravitantes a la hora de tomar la decisión de asumir una identidad, una historia y una posición política mapuche. Si bien 
las experiencias relatadas son variadas, existen algunos patrones comunes que se relacionan con la discriminación sufrida, con instancias educativas mapuche y/o con un fuerte lazo con un familiar directo que los conecte con ello.

Cuando Schütz (1993) se refiere al concepto "sentido mentado de la acción", habla del significado que el actor atribuye a su acción. Estos significados no son aislados de la trayectoria de vida de las personas, sino que se vinculan con un contexto geográfico y simbólico en el que se construye su identidad, sumado a aquellos hitos que marcan un quiebre epistemológico en sus vidas. Al respecto el autor señala: "Este significado subjetivo puede ser propio del intérprete, en cuyo caso debe remontarse en la memoria a las vivencias que tuvo en el momento de utilizar el signo y establecer su significado". (Schütz, 1993, p. 155).

Respecto de la discriminación sufrida por los jóvenes mapuche, es en el colegio donde se sufre la discriminación, con mayor frecuencia de parte de sus pares estudiantes y en algunos casos hasta por los profesores. Estas son relaciones coloniales expresadas en la retórica de la jerarquización social, explicadas por las diferencias biológicas innatas (Briones, 1998). Desde los tiempos de la colonización española, cuando los españoles criollos encuentran en la palabra "indio" o "negro" la manera de proyectar su continuidad esencial con los españoles peninsulares, justifican relaciones de dominación como la esclavitud y alientan la narración sobre la lucha entre razas superiores e inferiores. Esto se mantiene hasta hoy como un sistema/adscripción racializado.

$\mathrm{Al}$ respecto, las personas entrevistadas señalan que, en muchas ocasiones, quienes les hicieron saber su origen mapuche fueron los chilenos. A continuación, un cuadro de testimonios que grafican esta situación.

- Cuadro de discriminación

"los chilenos, los cabros chicos chilenos te hacían sentir que vo' era'i mapuche, mapuche o sea indio, y ser indio significaba hueón, ser tonto, borracho, sucio hueón, flojo". 
"a nosotros en el liceo po' o sea el tema de la discriminación en algunos casos, pero nunca de parte de los profesores, siempre de parte de los compañeros".

"afortunadamente también, porque como no era el primer apellido entonces ahí pasaba un poco más piola y la cuestión es que el que lo sabía, claro, igual molestaba e igual hueviaba".

"un humorista que el peñe- teñe no sé qué, nunca caché bien qué eran, pero de repente en el colegio 'aah peñe- teñe' ¿cachay? era como ah fome".

En este caso, se concibe la escuela como un espacio en el que se reproducen las relaciones coloniales que proyecta el Estado chileno desde 1884 (Caniuqueo et al., 2006), situación contradictoria con los principios que fundan la escuela sobre la base de la enseñanza equitativa, en la cual todos los niños son iguales. Siendo la escuela el lugar en el que se marcan las diferencias raciales y sociales, relaciones que se plasman en interacciones de subalternidad y superioridad.

Otro hito en la vida de nuestros entrevistados, que contribuye con un significado para sus prácticas políticas, es la inducción mediante instancias educativas, ya sean talleres o alguna materia específica, que les hizo reflexionar acerca de su historia biográfica. Esta situación es contradictoria, ya que muchas de estas instancias están enmarcadas dentro del colegio y también universidades, al igual que la discriminación.

Esto se explicaría porque, en la actualidad, no existe en Chile una política educativa seria que apunte hacia la interculturalidad, ya que existe la lógica de los proyectos, complementada con una suerte de "política de la no política", que consiste en apoyar las ideas o proyectos de otros que se acercan a la interculturalidad, en la medida en que la institución tenga la voluntad y las posibilidades de apoyar estas iniciativas. Por lo tanto, el operar de las políticas públicas en el área impide la promoción y desarrollo progresivo de las mismas, y no permite sustentar impactos relevantes en Santiago (Donoso, 2006). No obstante, cada taller (mapuche) que se realiza en alguna región del país, es entendido y configurado como un acto político de descolonización y resistencia a la desaparición total y muerte de las culturas originarias 
que aún existen o sobreviven en este mundo globalizado e interconectado.

- Cuadro de talleres y asignaturas de descolonización

"entonces ahí nos metimos varios digamos mapuches que andábamos dando
vuelta allá a ese taller y para mí fue un espacio de formación también impor-
tante".
"por un ramo que teníamos que era diferencial de lengua, y en esa diferencial
habían contenidos referentes a la identidad, del reconocerme yo como con un
origen, con un pasado, entonces ahí me di cuenta, jclaro! Tengo todo este
pasado, tengo toda esta historia familiar y además tengo este contexto que me
está rodeando, entonces tengo que reconocerme como tal, tengo que recono-
cerme como mapuche...".
"el dos mil tres entré a la U, yo creo que ahí entré y ahí entré ya, fue en ese
periodo que yo empecé como la hueá más, meterme en el tema más mapu-
che, cachay, que yo puedo decirte no... siempre lo tuve, siempre tuve el rollo
siempre me intereso en él, la hueá, cachay, mapuche, Lautaro... esa historia
entendi, pero yo no entendía ná el conflicto".

La búsqueda de la historia familiar y la socialización temprana en algunos casos, tardía en otros, resulta un momento importante también en la historia de vida de los jóvenes mapuche que viven en Santiago. Muchos de ellos deben responder preguntas tales como ¿qué significa tu apellido? ¿De qué parte del sur es tu familia? Y todo lo que hemos mencionado anteriormente -la discriminación, las inducciones mediante talleres de resistencia hacia lo mapuche- genera una necesidad de descubrir su propia historia familiar.

Estos procesos de socialización, descubrimiento e inducción a lo mapuche son universos simbólicos que, a su vez, "son procesos simbólicos de significación que se refieren a realidades que no son de la experiencia cotidiana" (Berger y Luckmann, 2001, p. 125). A medida que esta situación va provocando entusiasmo en el individuo por conocer su pasado y aprehender el universo simbólico mapuche, sus acciones y sus significados subjetivos van cambiando. Al respecto Berger y Luckmann señalan que "la identidad se legitima definitivamente situándola dentro del contexto de universos simbólicos" (Berger y Luckmann, 2001, p. 130). 
A continuación un cuadro testimonial de aprehensión de la identidad mapuche a partir de lazos familiares.

- Cuadro de aprehensión por lazo familiar

Oye pero yo también soy Nancupil! ....Y... ¿De dónde viene Ñancupil? y.... mi abuelo que... ¿Por qué está acá? ¿Por qué no viaja al sur? ¿Por qué no conozco a esa familia? Y... me empecé a cuestionar todas esas cuestiones po"".

"Mi abuela fallece el 2010 (...) claro, el 2010 fallece mi abuela (...) fue un hito importante, yo previamente el 2009-2008 cuando me vine de Valparaíso pa' acá 2007, 08, 09, conversé mucho con ella y lo que estaba escribiendo yo en términos de poesía tenía mucha relación con su historia de vida".

"Pero sí hay un hito propiamente tal, cuando nosotros ya decidimos participar en el ngillatun en Pudahuel, y entramos como familia a participar con nuestro küni, nuestra ramada... eh cosa que no se veía antes en los ochenta".

Todos estos elementos de las trayectorias de vida de los jóvenes mapuche que viven en Santiago dan sentido a sus prácticas políticas, ya que aprenden un sistema de significados que ha estado fuera de sus realidades cotidianas y que ahora se integra a sus significados subjetivos mediante la incorporación a un universo simbólico mapuche. Desde ahí deviene en el asumir su historia y su identidad mapuche legítimamente situada en la ciudad.

\section{Motivaciones de militancia y heterogeneidad de pensamiento}

Existen también motivaciones que incentivan a estos jóvenes a pertenecer a una organización mapuche que tenga fines políticos y realice actividades con sentido político en la ciudad. Las motivaciones son entendidas en este trabajo como un sistema de expectativas que representan el orden compartido de los significados simbólicos (Parsons, 1999) y que son normativos para las personas. "...dicho de otro modo: la mutualidad de las expectativas está orientada por el orden compartido de significados simbólicos" (Parsons, 1999, p. 11). Desde esta perspectiva, las motivaciones de los jóvenes mapuche para militar en una organi- 
zación mapuche en Santiago responden a expectativas políticas e identitarias. Según la información entregada por nuestros entrevistados, muchos de ellos estaban en búsqueda de una historia familiar con origen mapuche en el sur, pero que actualmente y desde hace décadas están viviendo en la ciudad.

Por esta razón, comenzaron a asistir a muchas actividades relacionadas con el mal denominado "conflicto mapuche". En este contexto, los conceptos "mapuche urbano" y sobre todo "diáspora mapuche" alcanzan una preponderancia política y también intelectual, dado el proceso de resignificación de lo mapuche en personas que viven en el exilio, lejos del territorio original.

Esta cuestión es uno de los puntos de mayor complejidad, dadas sus características al interior del movimiento mapuche en Santiago. La situación de diáspora (Ancan \& Calfío, 1999; Marimán, 1997) a menudo es aprehendida por el movimiento mapuche como una situación de exilio y no completamente como una situación identitaria; sin embargo, en este punto se enlaza la reflexión de la diáspora con el mapuche urbano, entendida como una cuestión político-identitaria, discusión que está permanentemente abierta al interior del movimiento.

- Cuadro discursos: mapuche urbano y diáspora

"Somos los primeros que tenemos estudios universitarios y nos atrevemos,
aquí en la ciudad o en la diáspora como muchos de nosotros la llamamos,
por no ser nuestro lugar de procedencia original y cultural, donde nos hemos
establecido dentro de comunidades locales, y que a diario nos formamos iden-
titariamente como mapuche".
"En otro punto, cierto es que representamos una diáspora (...) a veces deci-
mos incluso que vivimos una suerte de exilio. Cierto es también que, a pesar
de esto, algunas organizaciones urbanas tenemos una concepción de territo-
rio como un elemento vital para cualquier lucha autonomista".
"El retorno de la diáspora, claro entonces ya leyendo mucho en el colegio
desde la situación que vivía nuestro pueblo que era una diáspora y nosotros
también nos veíamos en esa serie, más allá de la migración campo-ciudad la-
tinoamericana, no lo habíamos conformado como político, porque la diáspora
es un fenómeno politico".


"cuando el Enrique toma el mundo urbano, entonces ahí hay una decisión de urbanidad mapuche, entonces yo dije esta wea' me representa mucho, o sea pucha por aquí voy yo, entonces ya me gustó mucho".

"sino que acá que había una hibridez rara que tomaba cuerpo y que además era genuino po' hueón o sea, no sé por qué nosotros íbamos a ser menos mapuche porque no estábamos en el sur po"'.

"la hueá política era en el sur, no existía el mapuche urbano y el rol del kilapan era sacar gente mapuche pero pa' la lucha en el sur ¿cachay?".

La resignificación de lo mapuche como aludiendo a sujetos socializados con la tecnología, globalizados e interconectados con distintos elementos externos a lo que sería la esencia mapuche, genera muchas contradicciones y tensiones en el universo simbólico que representa los significados inherentes a la cultura mapuche. Sin embargo, la concepción de "diáspora" en Clifford (1997) es un campo polifacético que, más que un control conceptual, conduce a rastrear sus variadas formas; por lo tanto, el concepto de "diáspora" aplicado a nuestro caso genera una apertura y una amplitud de las posibilidades de identidad mapuche.

La concepción de "diáspora" abarca incluso a la población mapuche que está lejos del movimiento político y cultural mapuche, es decir, esta reflexión está lejos de ser una categoría excluyente, sino todo lo contrario, integra a la gente mapuche que cree y adhiere a la fe cristiana evangélica, a los que viven en las diferentes poblaciones de Santiago, a los que participan de los clubes deportivos, los que gozan de un mejor pasar económico, los estudiantes universitarios, los barras bravas, los miembros de partidos políticos, incluso los mapuche homosexuales, un tema tabú dentro del mundo mapuche. La diáspora mapuche esta relegada a un lugar subalterno incluso dentro del movimiento mapuche. Los etnonacionalistas o "comunidad imaginada", que busca las coherencias étnicas, históricas y/o culturales, margina a quienes vivimos fuera de esas coherencias (Antileo, 2012).

Según Antileo, la concepción de "mapuche urbano" es diferente de la concepción de "diáspora", dado el uso que han hecho instituciones estatales indígenas (y/o las organizaciones mapu- 
che que se vinculan con el Estado) del término. Sin embargo en este trabajo, más allá del uso que han dado las instituciones estatales para asistir a las personas con sus políticas públicas multiculturales (Antileo, 2013), creo que ambas categorías se fusionan de manera complementaria, ya que una ("mapuche urbano") rompe con la tendencia a ruralizar lo mapuche, por lo tanto resignifica y problematiza la cuestión de lo mapuche, y finalmente "diáspora" aporta y legitima la pluralidad y heterogeneidad necesarias (Hall, 2000) que construyen eso que "realmente somos" o aquello en lo que nos hemos convertido, puesto que la historia ha intervenido en nosotros.

Otro elemento importante es que en el proceso ocurrieron muchos acontecimientos mediáticos, parte de las coyunturas políticas del movimiento, que fueron incidiendo en la decisión de militar en el movimiento y/o en algunas de estas organizaciones. A continuación algunos de los hechos coyunturales que ocurrieron en el proceso y que los jóvenes entrevistados identifican:

"la intención de hacer algo y bueno eh, se genera el movimiento estudiantil
y las conversaciones reflexiones llevan a, a que había que estar ahi, habia que
estar en un espacio donde se estaban tomando ciertas decisiones, ese más
menos fue en el fondo, claro se logró instalar, dejar instalado el tema".
"y claro, cuando en el '98 se dan estas circunstancias entre lo mapuche y lode
Pinochet y la asunción como senador vitalicio, empezó como más inquietudes
entre unos y otros, si había locos que tiraban su idea".
"empecé como a asistir a las actividades mapuches que se convocaban en
Santiago, y bueno, coincide con que ese fue un periodo muy álgido en el sur
(...), es el tiempo de la CAM; cachay, tiempo en que estaba todo más álgido,
salió hasta un comunicado declarando LA GUERRA... AL ESTADO CHI-
LENO".

Claro po'; comienzan las primeras huelgas de hambre... la Chepa, Matías Catrileo, Huenchunao, también huelga de hambre en Temuco, las primeras leyes antiterrorista eh, y también la necesidad de nosotros informarnos y empezar a leer, de estudiar y discutir el tema po'".

Uno de los elementos más relevantes que crea sentido en los jóvenes mapuche y representa una de las motivaciones más po- 
tentes para la decisión de militar al interior de una organización, es que no se desconoce la importancia que tiene la situación de conflicto que ocurre en las comunidades mapuche en el sur. En efecto, muchas actividades que se realizan en Santiago tienen como invitados a autoridades mapuche, como un lonko (primera autoridad de una comunidad) (Chihuailaf, 1999), un werken (vocero), o alguien involucrado en los acontecimientos vinculados a la causa mapuche.

Este elemento también aporta un sentido y un significado para la decisión de unirse a la causa mapuche. La mediaticidad que generan los enfrentamientos entre mapuche y Fuerzas Especiales de Carabineros, los procesamientos por Ley Antiterrorista, las tomas de fundos, quemas de camiones, los asesinatos de otros jóvenes mapuche, despiertan un interés en muchos jóvenes de Santiago.

\section{Capital militante, habitus político y matrices políticas}

El sociólogo Christian Martínez (2009) señala que habría una ingenua tendencia de homogeneizar el planteamiento político mapuche, y da cuenta de la existencia de una pluralidad de matrices de sentido político al interior del movimiento. Basados en el aporte de Martínez, planteamos que efectivamente existe una pluralidad de ideas políticas al interior del movimiento mapuche; no obstante, considero que la tendencia de homogeneizar el planteamiento político mapuche en ningún caso es ingenua, sino una visión colonial con intención explícita de homogeneizar aun los discursos de lucha mapuche.

La mención de una pluralidad de matrices de sentido es muy importante para este trabajo, dado que por "matriz" entiendo un sistema muy estructurado de significados (Schütz, 1993), que corresponden a un espacio físico específico. En palabras de Bourdieu (1995), una matriz es la estructura estructurante de la acción inserta en un campo específico. 
Las matrices de pensamiento político de la diáspora están configuradas por una serie de elementos que definen sus ideas. Por ejemplo la ubicación geográfica, el habitus político familiar, las trayectorias de vida individuales y colectivas. Al respecto podemos señalar que la diáspora mapuche tiene una herencia política familiar y un capital militante (Baronnet y Medina, 2013) vinculados a la izquierda chilena, enlazados a procesos históricos de organización popular insertos dentro de un contexto de poblaciones marginales en la Región Metropolitana, en comunas como Cerro Navia, La Pincoya, Peñalolén, Quinta Normal, La Granja, La Legua, etc.

Estos elementos van configurando los universos simbólicos de la diáspora mapuche que, según Berger y Luckmann (2001), están configurados por los elementos históricos y biográficos del individuo. Al respecto, los autores señalan que: "El universo simbólico se concibe como la matriz de todos los significados objetivados socialmente y subjetivamente reales; toda la sociedad histórica y la biografía de un individuo se ven como hechos que ocurren dentro de ese universo" (Berger y Luckmann, 2001, p. 125).

Siguiendo con esta descripción, las matrices de pensamiento político de la diáspora mapuche en Santiago tienen su origen en el proyecto ideológico mapuche propuesto por el Consejo de Todas las Tierras (CTT) en 1992, llamado "Autodeterminación". El historiador Fernando Pairican (2012) y el sociólogo Christian Martínez (2009), como mencionamos, coinciden en que el proyecto político del CTT fue una siembra ideológica para el movimiento mapuche y las futuras generaciones de mapuche.

El proceso de ideologización mapuche es descrito por los jóvenes entrevistados como "mapuchización". Además del proceso de autorreconocimiento identitario, existe un proceso de comprensión y posicionamiento de la cuestión política mapuche, a eso llamamos "mapuchización". A continuación un cuadro de relatos de los propios procesos. 
"ahí me fui mapuchizando, ahí entendí el proyecto mapuche, al final el proyecto político y se hacía eso, estaba un tiempo en el sur, los peñis me decían ya tiene que quedarse y era así po', y tenía que estar acá".

Carlos Antihual fue muy clave en mi mapuchización, cachay (...), me decía 'no, si estamos en guerra nosotros contra el Estado chileno', cachay, y a mí me empezó a gustar la hueá".

"yo estaba participando recién en lo mapuche ahí. O sea activamente con la cosa política (...) en la época que también la misma familia se empezó a mapuchizar".

"los hijos de mis hermanos de la organización también po', la Kinturay, Inayan, la Trawen, la Ailin, cachay. Son todos nombres mapuche que puede que parezca un detalle pero en el fondo ellos también están creciendo súper mapuchemente entre comillas".

"porque el loco va a ser menos mapuche porque nació en la población y tiene estas historias y tiene todas estas vivencias, y desde ahi quiere mapuchizarse y quiere, puta y hasta los locos mapuchizan a su familia po' hueón".

En el proceso de producción de los datos, los entrevistados expresaron que por mucho tiempo se sintieron como un chileno más, con conciencia social, pero no asumían su historicidad familiar ni se posicionaban como militantes de la causa mapuche. Para muchos mapuche este escenario se presenta como un conflicto identitario, y en algunos casos puede resultar incompatible ser chileno-mapuche, situación que está lejos de ser resuelta, dados los procesos de mapuchización extrema. Ello genera conflictos al interior del movimiento, por las historias familiares de muchos y el capital militante cimentado en procesos de organización popular y estudiantil chilenos.

"no sé, a lo mejor es mi crianza más de población; no sé, pero nunca he podido ser así como tan amapuchao o esa visión de lo mapuche digamos tampoco es lo mapuche enteramente".

"nunca tuve como un entorno muy mapuche, entonces yo hasta los dieciocho años yo era así una chilena como con conciencia social, cachay, no era más que eso. Y bueno, y de repente empecé a cachar un montón de cuestiones. Oye pero yo también soy Nancupil".

"mi papá no sentía ni mapuche, mi papá decía que éramos chilenos, cachay".

"una especie de separata que sacamos en un boletín que en una de esas separatas planteábamos una reflexión en torno al 19 de septiembre y con el titular "mapuche sí, chilenos no"; o "mapuches, puntos suspensivos, chilenos jamás". 
Con base en esta situación nuestros entrevistados consideran muy positivo que exista una especie de secesionismo o una preferencia por la identidad mapuche antes que por la chilena, dadas las circunstancias. No obstante, la reidentificación de los jóvenes mapuche en la ciudad no es suficiente a la hora de posicionarse como un actor político. Más aún, si este hecho no va acompañado de un proceso de formación política, es muy probable que aquel joven autorreconocido mapuche pueda resultar ser un elemento negativo al interior del movimiento, al caer en discursos chauvinistas (Goffman, 2006) y hasta etnonacionalistas.

Si bien los puntos negativos de la sobreideologización pueden llevar a la estigmatización, el racismo y el odio, la siembra ideológica del CTT está orientada hacia la autodeterminación del pueblo mapuche, proyecto político altamente secesionista, pero con matices de radicalidad que se asemejan mucho a las matrices de pensamiento político descritas. A continuación un cuadro de lo que los entrevistados entienden por autonomía y autodeterminación:

"esas ideas politicas yo creo que se basan en, bueno en varias cosas, una de
ellas yo creo que tiene que ver con la autonomía de la organizaciones o con
la autonomía del movimiento mapuche, yo creo que la autonomía no es un
fin, la autodeterminación yo creo que se alcanza cierto como una meta, pero
en ese proceso se generan procesos de autonomía que son fundamentales".
"a mí la línea (política) que me agrada es la linea del control territorial, con-
trol territorial como método para llegar a la autodeterminación, cachay. Re-
cuperaciones de tierra, formación de personas, cuadros, en general... pasar
del discurso a la práctica, también política, espiritual, todo eso... el control
territorial como reconstrucción del Lof y de ahí las bases de la autodetermi-
nación de nuestro pueblo, yo creo en eso".
"en la actualidad, la elección hasta de concejales mapuche, la elección de al-
caldes mapuche y que provienen precisamente de corrientes que validan la
autonomía y la autodeterminación y eso me parece más interesante aún...
que se diversifiquen y que se vivan en la práctica, también experiencias de
autonomí, sobre todo a partir del control, por ejemplo, de la municipalidad".
"Crear una institucionalidad desde lo mapuche, pero entender que, como es-
tamos en el siglo XXI, también entender que por ejemplo, no sé, el tema de los
loncos, de hacer esto, esto los trawun, lo koyantun, o hacer estas reuniones
más grandes, los ayllarehue, y llegar por ejemplo a ser una voz a nivel, como
lazos con instituciones indigenas, con los mapuches, con lo estatal, hacer un
lazo para que también sean representados a nivel ya desde el mismo congreso". 
Respecto de las ideas de autodeterminación del pueblo mapuche, podemos decir que tiene distintos grados de radicalidad en la acción, pero todos son válidos dentro de las distintas ramas políticas del mapuchismo. Algunos optan por la autogestión como medio hacia la autodeterminación, otros por el control del territorio y los medios de producción propia, y otros tomando posesión de las entidades de poder existentes, como los municipios.

En tanto, el concepto "mapuchismo" es utilizado por los jóvenes e integrantes en general del movimiento para referirse a la población mapuche santiaguina movilizada, que configura las ideas en torno al proyecto político de autodeterminación. Si bien todos nuestros entrevistados señalan que la autodeterminación es el objetivo político común, el camino para llegar a ese destino es distinto, dada la heterogeneidad de las organizaciones que componen el movimiento mapuche y/o mapuchismo.

\section{Conclusión}

Desde los primeros años de la presencia mapuche en Santiago, su participación política ha sido significativa, desde los sindicatos y los partidos políticos hasta los centros culturales, los colectivos de estudiantes y las organizaciones sociales. La diáspora mapuche ha cambiado sus prácticas políticas en tanto los tiempos sociales también han ido cambiando. En la actualidad los jóvenes de la diáspora conforman mayoritariamente el movimiento político y social mapuche, y son ellos quienes proyectan las ideas propias de la situación mapuche.

Los jóvenes mapuche que viven en Santiago y pertenecen o pertenecieron a una organización atribuyen distintos sentidos a sus prácticas políticas; por lo tanto, podemos afirmar que existe una ampliación del significado político del movimiento mapuche, es decir, el significado político no está solamente en un acto cívico o militante, o en una acción de protesta, sino en cada actividad que simbolice una reivindicación histórica en y para las trayectorias de vida de los jóvenes. 
Uno de los desafíos del mapuchismo en el proceso de construcción de la autodeterminación es establecer vínculos con los movimientos sociales "desde abajo" de la sociedad chilena. En la experiencia que hemos registrado existen vínculos interesantes con el movimiento anarquista de fines de los noventa y principios de la primera década de 2000, y con el movimiento estudiantil chileno; por lo tanto, es necesaria una sintonía con los movimientos sociales chilenos, dados los diferentes campos en los que se instalan las demandas y propuestas y en donde se puede desarrollar un trabajo político que genere un aporte real al proyecto sociopolítico mapuche. Pese a la necesidad de establecer puntos en común en las ideas políticas del movimiento mapuche, se requiere también la pluralidad de las matrices políticas para permitir una mayor amplitud de campos en la sociedad.

Finalmente, dar cuenta de un proceso de movilización indígena popular mapuche, en un contexto de ciudad capital como Santiago de Chile y con presencia fundamentalmente juvenil, es muy relevante para el análisis de los movimientos indígenas latinoamericanos, basados principalmente en contextos rurales campesinos. Ello rompe con la tendencia de ruralización de las luchas indígenas del continente, dando cuenta también de los procesos de mapuchización y configuración del mapuchismo en Chile.

\section{Referencias}

Ancan, J. y Calfio, M. (1999). El retorno al país Mapuche. Preliminares para una utopía por construir. Liwen, 5, 43-79.

Aniñir, D. (2005). Mapurbe venganza a raíz. Santiago: Odiokracia Autoediciones.

Antileo, E. (2012). Nuevas formas de colonialismo: Diáspora mapuche y el discurso de la multiculturalidad. (Tesis de Magíster). Universidad de Chile, Santiago de Chile.

Antileo, Enrique (2013). Políticas indígenas, multiculturalismo y el enfoque estatal indígena urbano. Historias mapuche: Perspectivas para (Re) pensar la Autodeterminación. Revista de historia social y de las mentalidades, 17(1), 133-161. 
Baronnet, B. y Medina, P. (2013). Movimientos decoloniales en América Latina: un balance necesario desde las pedagogías interculturales emergentes en México. Autonomía, territorio y educación propia. Multiculturalismo y educación 2002 - 2011. Estado del conocimiento. México DF: ANUIES.

Bengoa, J. (2000). La Emergencia Indígena en América Latina. Santiago: Fondo de Cultura Económica.

Bengoa, J. (1999). Historia de un conflicto. Santiago: Grijalbo.

Berger, P. y Luckmann, T. (2001). La construcción social de la realidad. Buenos Aires, Argentina: Amorrortu editores.

Bourdieu, P. y Wacquant, L. (1995). Respuestas. Por una antropología reflexiva. México DF: Editorial Grijalbo.

Briones, C. (1998). La alteridad del "cuarto mundo". Una deconstrucción antropológica de la diferencia. Buenos Aires, Argentina: Ediciones del Sol.

Caniuqueo, S., Levil, R., Mariman, P. y Millalen, J. (2006). j... Escucha, Winka...! Santiago: LOM ediciones.

Curivil, F. (2006). Asociatividad mapuche en espacio urbano, Santiago 1940 1970. (Tesis de Pregrado). Facultad de Filosofía y Humanidades, Universidad de Chile, Santiago de Chile.

Chihuailaf, E. (1999). Recado confidencial a los chilenos. Santiago de Chile: Editorial LOM.

Clifford, J. (1997). Itinerarios transculturales. Barcelona: Gedisa Editorial.

Donoso, A. (2006). Interculturalidad y Políticas Públicas en Educación. Reflexiones desde Santiago de Chile. Estudios Pedagógicos, 32(1), 1-8.

Feixa, C. (2010). ¿Una juventud global? Identidades híbridas, mundos plurales. Seminario niñez, juventud y consumo. Santiago de Chile.

Goffman, E. (2006). Estigma: la identidad deteriorada. Buenos Aires, Argentina: Amorrortu editores.

Hall, S. (2010 [2000]). La cuestión multicultural. En S. Hall, E. Restrepo, C. Walsh, y V. Vich (eds). Sin garantías. Trayectorias y problemáticas en estudios culturales. Instituto de Estudios Sociales y Culturales; Universidad Andina Simón Bolívar; Instituto de Estudios Peruanos.

Imilan, W. y Álvarez, V. (2008). El pan mapuche. Un acercamiento a la migración mapuche en la ciudad de Santiago. Revista Austral de Ciencias Sociales [online], p. 32. 
Instituto Nacional de Estadísticas (2012). Estadísticas sociales de pueblos indígenas. Censo 2012. Santiago: INE.

Martínez, C. (2004). Los desafíos del movimiento mapuche. Política étnica, redes y proyecto alternativo, 1967-1995. (Tesis de Doctorado). El Colegio de México, México.

Martínez, C. (2009). Transición a la democracia, militancia y proyecto étnico. La fundación de la organización mapuche Consejo de Todas las Tierras (1978-1990). Estudios Sociológicos, XXVII (80), 595-618.

Osorio, L. (2009). De Chorizo a weichafe: nuevos elementos culturales en la identidad mapuche en Santiago, 1997-2009. Recuperado el 26 de enero de 2016 de http:/ / www.tesis.uchile.cl/tesis / uchile/2009/fi-osorio_li/html/index-frames.html

Pairican, F. y Álvarez, R. (2011). La Nueva Guerra de Arauco: La Coordinadora Arauco-Malleco y los nuevos movimientos de resistencia Mapuche en el Chile de la Concertación (19972009). En M. Modonesi, y J. Rebón (cood.) Una década del movimiento. Luchas populares en América Latina en el amanecer del siglo XXI. Buenos Aires: Ediciones CLACSO.

Pairican, F. (2012). Sembrando Ideología: el Aukiñ Wallmapu Ngulam en la transición de Aylwin (1990-1994). SudHistoria: Revista digital en estudios desde el sur, (4), 12-42.

Parsons, T. (1999). El sistema social. Madrid: Alianza editorial.

Pérez, L. y Valladares, L. (2014). Juventudes Indígenas. De hip hop y protesta social en América Latina. México DF: Editoriales INAH.

Revista Rufián (2012). Warriache. Crónicas de la resistencia mapuche en la ciudad. 2 (11). Recuperado el 22 de agosto de: http:www. rufianrevista.org.

Saavedra P., A. (2002). Los mapuches en la sociedad chilena actual. Santiago: LOM Ediciones, Universidad Austral.

Saavedra, A. (2000). Notas sobre la población Mapuche Actual. Santiago: LOM ediciones, Universidad Austral.

Sandoval, E. (2013). Educaciones interculturales en México. Buenos Aires: Estudios Sociológicos Editora.

Schütz, A. (1993). La construcción significativa del mundo social. Introducción a la sociología comprensiva. España: Ediciones Paidós.

Valdés, M. (2003). Migración Mapuche y No Mapuche, notas prelimina- 
REVISTA TEMAS SOCIOLÓGICOS Nº $19 \cdot 2015 \cdot$ ISSN 0719-6458 · pp. 133 - 167

res de investigación. Biblioteca virtual universal [online]. Recuperado el 26 de enero de 2016 de http: / / www.biblioteca. org.ar/libros/8855.pdf

Villalobos, S. (2007). Activismo mapuche y posdictadura chilena: el potencial afectivo del conflicto. Cuadernos de Literatura, 11(22), 108-122. 